\title{
Water intake and beverage consumption of pre-schoolers from six European countries and associations with socio-economic status: the ToyBox-study
}

\author{
An-Sofie Pinket ${ }^{1, *}$, Marieke De Craemer ${ }^{2}$, Lea Maes ${ }^{1}$, Ilse De Bourdeaudhuij ${ }^{2}$, \\ Greet Cardon ${ }^{2}$, Odysseas Androutsos ${ }^{3}$, Berthold Koletzko ${ }^{4}$, Luis Moreno ${ }^{5}$, Piotr Socha ${ }^{6}$, \\ Violeta lotova ${ }^{7}$, Yannis Manios ${ }^{3}$ and Wendy Van Lippevelde ${ }^{1}$ on behalf of the \\ ToyBox-study group \\ 'Ghent University, Department of Public Health, Unit Health Promotion, De Pintelaan 185 - 4K3 lokaal 036, 9000 \\ Gent, Belgium: ${ }^{2}$ Department of Movement and Sport Sciences, Ghent University, Ghent, Belgium: ${ }^{3}$ Department of \\ Nutrition and Dietetics, Harokopio University, Athens, Greece: ${ }^{4}$ Dr. von Hauner Children's Hospital, Ludwig- \\ Maximilians-University of Munich, Munich, Germany: ${ }^{5}$ GENUD (Growth, Exercise, NUtrition and Development) \\ Research Group, University of Zaragoza, Zaragoza, Spain: 'The Children's Memorial Health Institute, Warsaw, \\ Poland: ${ }^{7}$ Clinic of Paeditric Endocrinology, UMHAT 'St. Marina', Varna, Bulgaria
}

Submitted 13 January 2015: Final revision received 10 November 2015: Accepted 23 November 2015: First published online 18 December 2015

\begin{abstract}
Objective: To study the quantity and quality of water intake from beverages among pre-schoolers and investigate associations with gender and socio-economic status (SES).

Design: Kindergarten-based cross-sectional survey within the large-scale European ToyBox-study. A standardized protocol was used and parents/ caregivers filled in sociodemographic data and a semi-quantitative FFQ.

Setting: Kindergartens in six European countries (Belgium, Bulgaria, Germany, Greece, Poland and Spain).

Subjects: European pre-schoolers (aged 3.5-5.5 years) and their parents/caregivers ( $n$ 7051).

Results: Mean water intake was $1051 \mathrm{ml} / \mathrm{d}$; plain water, $547 \mathrm{ml} / \mathrm{d}$; plain milk, $241 \mathrm{ml} / \mathrm{d}$; other fruit juice, $104 \mathrm{ml} / \mathrm{d}$; pure fruit juice, $59 \mathrm{ml} / \mathrm{d}$; soft drinks, $55 \mathrm{ml} / \mathrm{d}$; tea, $45 \mathrm{ml} / \mathrm{d}$; sugared and chocolate milk, $37 \mathrm{ml} / \mathrm{d}$; smoothies, $15 \mathrm{ml} / \mathrm{d}$; and light soft drinks, $6 \mathrm{ml} / \mathrm{d}$. Boys had a higher water intake than girls due to a higher consumption of plain water, but more importantly to the consumption of beverages of less quality. Lower-SES pre-schoolers scored better on quantity than high-SES pre-schoolers, but as a consequence of consumption of sugared beverages. Nevertheless, the associations differed by country.

Conclusions: The water intake from beverages did not meet the European Food Safety Authority standard of $1280 \mathrm{ml} / \mathrm{d}$; especially in Western European countries water intake from beverages was low. The most important water sources were plain water, milk and fruit juices. Interventions aiming at a proper and sufficient water intake should focus on both quantity and quality. Messages about water and water sources should be clear for everyone and interventions should be sufficiently tailored.
\end{abstract}

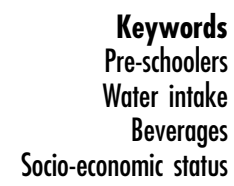

Keywords

Pre-schoolers

Beverages

Socio-economic status
To date, few studies report on water intake from beverages in pre-school children ${ }^{(1)}$. Some studies report on children's sugared beverage consumption, but very few focus on water intake from other beverages ${ }^{(2,3)}$. Also, most studies focus on older children instead of pre-schoolers. However, the importance of a healthy diet, and thus an optimal water intake and healthy beverage choices, starts early in life since dietary habits are being formed at a young age and track into adolescence and adult life ${ }^{(4-6)}$. The limited studies investigating water intake in pre-school children make it hard to set overall water requirements. However, the European Food Safety Authority (EFSA) recommends an adequate intake of total water (water from plain water, beverages and food) of $1300 \mathrm{ml} / \mathrm{d}$ for 2- to 3-year-old children and $1600 \mathrm{ml} / \mathrm{d}$ for 4 - to 8 -year-old children. This guideline is derived from observed intakes 
corrected for a desirable water-energy relationship and corrected for inter-individual variation ${ }^{(7)}$. The present study focused solely on water intake from beverages (i.e. plain water and other beverages) since water intake through beverages is the most important source. Only $20 \%$ of total water intake comes from food ${ }^{(8)}$. Nevertheless, also the quality of the beverages plays a notable role in a healthy lifestyle ${ }^{(8)}$.

Comparing results of studies on water intake and comparing these results with the set norms is hampered by differences in reporting and differences in the instrument used to measure the intake (e.g. $24 \mathrm{~h}$ recall, FFQ). However, from several studies in pre-schoolers it can be deduced that pre-schoolers' water intake is not sufficient, given the earlier mentioned water standards ${ }^{(4,9,10)}$. Nevertheless, given the great variety of beverage items that were measured in the different studies, it is difficult to compare. So, it is also complicated to compare pre-schoolers' water intake with the suggested standards. In addition, plain water, as an important source of water, is often replaced by sugared beverages ${ }^{(11,12)}$. Data from the National Health and Nutrition Examination Survey 2003-2006 in the USA revealed that soft drinks and fruit drinks were the two main sources of added sugar in children and adolescents ${ }^{(13)}$. A study by Rader et al. indicated that about one in five children consume excessive energy from sugared beverages and LaRowe et al. showed that total energy intake from beverages is increasing in children ${ }^{(14,15)}$. Additionally, few studies examine the relationship between beverage consumption and gender and socio-economic status (SES). However, differences by SES and gender may be important to target subgroups in interventions. Some studies found a difference in soft drink consumption by gender, namely boys were found to be drinking more soft drinks and fruit juices than girls, while other studies found no differences according to gender ${ }^{(9,16,17)}$. A more detailed look at differences in quantity and especially quality of beverages can provide interesting findings. Moreover, most previous research has found higher obesity prevalence in children of lower SES, which is often associated with a difference in food intake or consumption of sweetened beverages, compared with peers of high-SES backgrounds ${ }^{(18-20)}$. The differences in water intake from multiple beverages according to SES, however, have not been thoroughly investigated yet. Sohn et al. found that low-SES children consumed more plain water and less milk than mediumand high-SES children between 1 and 10 years of age in the $\mathrm{USA}^{(21)}$. More recent studies and research on European children is missing. Consequently, looking into differences in water intake from multiple beverages according to SES in European pre-schoolers is expected to yield new insights.

The first purpose of the present study was to study the quantity of water intake from beverages among pre-schoolers in six European countries. The second study aim was to provide an overview of the volume and quality of beverages consumed by pre-schoolers in these six European countries. Third, the associations between water/beverage intake and gender and SES (educational level of the mother) were investigated. Data were collected in the context of the ToyBox-study (Multifactorial evidence-based approach using behavioural models in understanding and promoting fun, healthy food, play and policy for the prevention of obesity in early childhood) in six European countries (Belgium, Bulgaria, Germany, Greece, Poland and Spain). These three aims were investigated in the total sample and in all six countries separately.

\section{Methods}

\section{Study background}

The ToyBox-study is a European Union-funded large-scale study of pre-schoolers (3.5-5.5 years old) and their families from six European countries (Belgium, Bulgaria, Germany, Greece, Poland and Spain). It aimed to develop and evaluate a kindergarten-based, family-involved intervention to prevent overweight and obesity in pre-school children (www.toybox-study.eu) ${ }^{(22)}$. For the present study, the baseline data from the ToyBox-study were used.

The ToyBox-study was approved by ethics committees in all six European countries, in line with national regulations (i.e. the Ethical Committee of Ghent University Hospital (Belgium), the Committee for the Ethics of the Scientific Studies (KENI) at the Medical University of Varna (Bulgaria), Ethikkommission der LudwigMaximilians-Universität München (Germany), the Ethics Committee of Harokopio University of Athens (Greece), the Ethical Committee of Children's Memorial Health Institute (Poland) and CEICA (Comité Ético de Investigación Clínica de Aragón (Spain)).

\section{Participants}

Pre-school children between 3.5 and 5.5 years old were recruited from six European countries: Belgium, Bulgaria, Germany, Greece, Poland and Spain. These children and their families were recruited at kindergartens, day-care centres or pre-school settings, depending on the country regulations and legislation. Precisely, in Germany, Bulgaria, Spain and Poland children/families were recruited from kindergartens, in Greece from kindergartens and day-care centres and in Belgium from pre-school settings. In order to avoid confusion for the reader, all these settings (kindergartens, day-care centres, pre-school settings) are referred to as 'kindergartens' in the current paper. Kindergartens were recruited from different sociodemographic backgrounds within each of the provinces (West Flanders and East Flanders in Belgium; Varna in Bulgaria; Bavaria in Germany; Attica in Greece; Warsaw 
and surroundings in Poland; Zaragoza in Spain). Lists of all municipalities that exist within the selected provinces were created with information on the SES variables. Tertiles including three different sociodemographic groups were created based on the selected SES variables and each country randomly selected five municipalities per SES status: five municipalities for low SES, five for medium SES and five for high SES. Then, kindergartens within these randomly chosen municipalities were randomly selected (with the exclusion of the lowest $20 \%$ of the kindergartens with the smallest number of pupils).

To account for possible drop-out, each country had to recruit an initial number of 1100 pre-schoolers, which would make a total sample of 6600 pre-school children across all six countries. Data collection occurred between May and June 2012. Parents/caregivers were asked for written consent for the participation of their child and themselves in the study. Only pre-schoolers whose parents/caregivers gave their consent were included in the study. Detailed sampling methods have been described elsewhere ${ }^{(23)}$.

\section{Measures}

\section{Beverage intake}

Parents/caregivers were asked to describe the child's usual food and beverage habits over the last 1-2 months in an FFQ for young children, based on a previously validated FFQ developed by Huybrechts et al. ${ }^{(24)}$. The FFQ of Huybrechts et al. was developed to assess pre-school children's food and beverage group estimates and consumption patterns. It has been validated in general and this includes the various types of beverage covered in the FFQ and used in the present study. Results of the validation of the FFQ by Huybrechts et al. showed moderate to good reproducibility (intra-class correlation coefficients ranged from 0.62 to 0.79 ) and good relative validity (Spearman correlation coefficients ranged from 0.56 to 0.65$)$ for beverages ${ }^{(24)}$.

Only the items about beverage consumption were used in the present study. The selected beverages were plain water (both tap and bottled water), soft drinks, light soft drinks, pure fruit juice (home-made and freshly squeezed fruit juice), other fruit juice (pre-packed/bottled fruit juice), tea, smoothies (all kinds), plain milk, and sugared and chocolate milk. For each of these beverages, the frequency of consumption was asked. Response categories were: 'never or less than once per month', '1-3 days per month', '1 day per week', '2-4 days per week', '5-6 days per week' and 'every day'. Next, the average consumption per day was asked. The response categories were ' $100 \mathrm{ml}$ or less', '100-200 ml', '200-300 ml', '300-400 ml', ‘ $400-500 \mathrm{ml}$ ', '500-600 ml', ‘600-700 ml', '700-800 ml', '800-900 ml', '900-1000 ml' and ' $1000 \mathrm{ml}$ or more'. From these data, the average amount of the different beverages in $\mathrm{ml} / \mathrm{d}$ was calculated by multiplication of the number of days per week and the amount per day in millilitres divided by 7 . The water intake from these beverages was calculated based on the Dutch food composition database ${ }^{(25)}$, by multiplication of the average amount in $\mathrm{ml} / \mathrm{d}$ and the amount of water per millilitre of each beverage.

\section{Overweight}

Pre-schoolers' weight and height were measured by the ToyBox-study researchers as has been described elsewhere ${ }^{(26)}$. Each measurement was conducted a minimum of two times and mean height and weight were calculated. Based on these measurements, BMI was calculated. Next, the pre-schoolers were categorized into two categories based on the age- and sex-specific cut-off levels of Cole and Lobstein: being overweight or obese and not being overweight or obese ${ }^{(27)}$.

\section{Socio-economic status}

Education of the parents/caregivers was determined in the core questionnaire. The educational level of the mother was used as the SES indicator. The educational level was dichotomized into lower ( $\leq 14$ years of education) and high ( $>14$ years of education) SES, similar to the SES measure used in the large-scale European ENERGY (EuropeaN Energy balance Research to prevent excessive weight Gain among Youth) study, which distinguishes families with a mother who has completed medium or higher education, college or university training from other families ${ }^{(28)}$.

\section{Other sociodemographic variables}

Gender and date of birth were reported by one of the parents/caregivers of the child in the core questionnaire. Children's age was computed based on the date of birth and the date when the questionnaire was completed. All questionnaires are available on the ToyBox-study website (www.toybox-study.eu) and in the ToyBox supplement issue $^{(29)}$.

\section{Water standard}

The EFSA recommendation of $1600 \mathrm{ml} / \mathrm{d}$ for boys and girls aged 4-8 years was chosen as the norm in the present study $^{(4)}$. Combined with the knowledge that $80 \%$ of total water intake comes from beverages, $1280 \mathrm{ml} / \mathrm{d}$ was used to set a standard for water intake from beverages ${ }^{(8)}$.

\section{Statistical analyses}

First, descriptive statistics were performed using the statistical software package IBM SPSS Statistics for Windows version 21.0 to investigate: (i) the characteristics of participants (number, mean age, percentage of males and percentage of lower-SES pre-schoolers); (ii) the daily intake of total water and of nine types of beverage; (iii) the average percentage of daily total water intake from the different types of beverage; and (iv) the percentage of 
participants who reached the EFSA standard in the total sample and in each country separately.

Next, multilevel analyses were performed using MLWiN version 2.30 (Centre for Multilevel Modelling, University of Bristol, Bristol, UK) to assess differences in means of proportions according to gender and SES. To take into account clustering of pre-school children in kindergarten classes and of kindergarten classes in kindergartens, multilevel modelling was used (three levels: pre-schooler, kindergarten class and kindergarten). Differences by SES and gender were tested in the total sample and by country, with intake (such as plain water or total water intake) as dependent variable and SES/gender as independent variable. The analyses for both SES and gender are adjusted for age and overweight. To perform analysis in the total sample, country was added as a fourth level. Pre-school children who had at least one valid measurement for frequency and portion size of the different beverages were included. This means that pre-schoolers who had no valid data (both on frequency and portion size) on all nine beverages were excluded from the study ( $n$ 51). Differences were tested in the total sample and in all six country-specific samples separately. Significance level was set at $P<0 \cdot 05$.

\section{Results}

\section{Population characteristics}

Table 1 presents the characteristics for the total sample and for each country separately. The total sample included 7051 pre-schoolers (mean age 4.8 (SD 0.4) years, 52.0\% boys) from six European countries, $40 \cdot 1 \%$ had a mother with a lower level of education ( $\leq 14$ years of education). The Polish sample counted the fewest pre-schoolers of lower-SES mothers (21.0\%), the Greek sample the most (51.6\%).

\section{Water intake}

Water intake from different beverages

Table 2 shows the average daily amounts (in millilitres) of the different beverages that were consumed and the contribution (percentage) to the total water intake from plain water and the other beverages. The average amount of water from plain water and beverages for the total sample was $1050.5 \mathrm{ml} / \mathrm{d}$. In the Spanish sample, $50.4 \%$ of the pre-schoolers met the standard of $1280 \mathrm{ml}$ water from beverages daily. In Belgian pre-school children, this was only $8.1 \%$. The highest proportion of daily water intake came from plain water $(51.2 \%)$, followed by milk (plain and sugared; $23.2 \%$ ) and fruit juice (pure and pre-packed; $14.3 \%)$. About $5 \%$ of the water intake came from soft drinks. Consumption of light soft drinks was low. Plain water consumption was especially low in Poland, but Polish pre-schoolers drank a high amount of tea and soft drinks. Bulgarian pre-school children had low plain milk consumption. Pure fruit juice consumption was especially high in Greece, while consumption of other fruit juice was particularly high in Poland.

\section{Water intake by gender}

Some significant differences in water intake and beverage consumption by gender were found (see Table 3). Male pre-schoolers of the total sample had a higher water intake from beverages than their female peers. This result was confirmed in all country-specific samples, except for the Belgian sample. In the total sample, male pre-school children drank more plain water, other fruit juice, and sugared and chocolate milk than pre-school girls. For plain water, significant gender differences were found also for Bulgarian, Greek and Spanish pre-schoolers, with males having higher intakes than females. No significant differences by gender were found for other fruit juice in the country-specific samples. For sugared and chocolate milk, significant differences were confirmed only for Belgian children. Bulgarian pre-school boys drank more tea than their female peers, while the opposite was seen in Greek pre-schoolers. In the total sample, no significant gender differences in tea consumption could be found.

Water intake by educational level of the mother

Water intake differed significantly by SES (see Table 4). Mixed results were found for total water intake from beverages. Pre-school children whose mother had a lower level of education consumed more water from beverages than pre-school children whose mother

Table 1 Characteristics of the total sample and of each country separately. European pre-schoolers (aged 3.5-5.5 years) and their parents/ caregivers ( $n$ 7051), ToyBox-study, May-June 2012

\begin{tabular}{|c|c|c|c|c|c|c|c|}
\hline & Total & Belgium & Bulgaria & Germany & Greece & Poland & Spain \\
\hline $\begin{array}{l}n \\
\text { Age (years) }\end{array}$ & 7051 & 940 & 782 & 1266 & 1804 & 1386 & 873 \\
\hline Mean & $4 \cdot 8$ & 4.4 & 4.9 & 4.5 & 4.9 & 4.9 & 4.9 \\
\hline SD & 0.4 & 0.5 & 0.3 & 0.6 & 0.3 & 0.3 & 0.3 \\
\hline Gender (\% male) & $52 \cdot 0$ & $52 \cdot 2$ & $50 \cdot 3$ & $51 \cdot 7$ & $51 \cdot 2$ & 53.0 & $54 \cdot 2$ \\
\hline SES (\% lower SES)† & $40 \cdot 1$ & 34.8 & $40 \cdot 7$ & $51 \cdot 2$ & $51 \cdot 6$ & 21.0 & 35.6 \\
\hline
\end{tabular}

SES, socio-economic status.

†SES indicator is years of school education of the mother: lower, mother of the child has $\leq 14$ years of education. 
Table 2 Daily intakes of nine types of beverage $(\mathrm{ml})$, daily intake of water from beverages (total water; $\mathrm{ml}$ ), average percentage of daily water intake from beverages for the different types of beverage and percentage of participants who reached the EFSA standard, for the total sample and each country separately. European pre-schoolers (aged 3.5-5.5 years) and their parents/caregivers ( $n$ 7051), ToyBox-study, May-June 2012

\begin{tabular}{|c|c|c|c|c|c|c|c|c|c|c|c|c|c|c|}
\hline & \multicolumn{2}{|c|}{ Total } & \multicolumn{2}{|c|}{ Belgium } & \multicolumn{2}{|c|}{ Bulgaria } & \multicolumn{2}{|c|}{ Germany } & \multicolumn{2}{|c|}{ Greece } & \multicolumn{2}{|c|}{ Poland } & \multicolumn{2}{|c|}{ Spain } \\
\hline & $\mathrm{ml}$ & $\% \dagger$ & $\mathrm{ml}$ & $\% †$ & $\mathrm{ml}$ & $\% †$ & $\mathrm{ml}$ & $\% \dagger$ & $\mathrm{ml}$ & $\% \dagger$ & $\mathrm{ml}$ & $\% \dagger$ & $\mathrm{ml}$ & $\% †$ \\
\hline Plain water & 547 & $51 \cdot 2$ & 414 & $49 \cdot 2$ & 662 & $64 \cdot 9$ & 496 & $55 \cdot 2$ & 628 & $50 \cdot 8$ & 394 & 37.5 & 740 & $57 \cdot 7$ \\
\hline Tea & 45 & $4 \cdot 6$ & 5 & 0.6 & 59 & $5 \cdot 7$ & 54 & $5 \cdot 6$ & 8 & 0.7 & 134 & 13.4 & 2 & 0.2 \\
\hline Soft drinks & 55 & 4.9 & 62 & $6 \cdot 8$ & 34 & 2.9 & 41 & 4.5 & 13 & 0.9 & 155 & $13 \cdot 1$ & 15 & $1 \cdot 1$ \\
\hline Light soft drinks & 6 & 0.6 & 15 & $1 \cdot 7$ & 12 & 0.9 & 5 & 0.6 & 3 & 0.4 & 4 & 0.3 & 4 & 0.3 \\
\hline Pure fruit juice $\ddagger$ & 59 & 4.8 & 16 & 1.5 & 47 & 4.0 & 62 & 6.4 & 114 & 8.6 & 28 & $2 \cdot 3$ & 43 & 3.0 \\
\hline Other fruit juice§ & 104 & 9.5 & 93 & $10 \cdot 1$ & 98 & 8.7 & 104 & 11.7 & 70 & $5 \cdot 3$ & 175 & $15 \cdot 4$ & 77 & 5.5 \\
\hline Smoothies & 15 & $1 \cdot 2$ & 2 & 0.2 & 11 & 0.9 & 2 & 0.2 & 9 & 0.6 & 25 & $2 \cdot 2$ & 49 & $3 \cdot 2$ \\
\hline Plain milk & 241 & $20 \cdot 1$ & 202 & 21.2 & 105 & 9.4 & 120 & $12 \cdot 9$ & 415 & 31.7 & 163 & $14 \cdot 4$ & 341 & $24 \cdot 3$ \\
\hline Sugared and chocolate milk & 37 & $3 \cdot 1$ & 84 & 8.7 & 33 & 2.6 & \multirow{2}{*}{\multicolumn{2}{|c|}{869}} & 15 & $1 \cdot 0$ & 17 & 1.4 & 79 & 4.7 \\
\hline Total water $(\mathrm{ml}) \|$ & \multicolumn{2}{|c|}{1051} & \multicolumn{2}{|c|}{840} & \multicolumn{2}{|c|}{1022} & & & \multicolumn{2}{|c|}{1205} & \multicolumn{2}{|c|}{1032} & \multicolumn{2}{|c|}{1278} \\
\hline Norm (\%)ף & \multicolumn{2}{|c|}{$28 \cdot 1$} & \multicolumn{2}{|c|}{$8 \cdot 1$} & \multicolumn{2}{|c|}{$24 \cdot 0$} & \multicolumn{2}{|c|}{$14 \cdot 1$} & \multicolumn{2}{|c|}{$42 \cdot 2$} & \multicolumn{2}{|c|}{$24 \cdot 4$} & \multicolumn{2}{|c|}{$50 \cdot 4$} \\
\hline
\end{tabular}

EFSA, European Food Safety Authority.

tPercentage of total water.

†Home-made, freshly squeezed.

§Pre-packed/bottled.

IICalculated from the water content from the various beverages. Water content based on the Dutch food composition database ${ }^{(25)}$ : water, $100.0 \%$; tea, $99.9 \%$; soft drinks, $89.9 \%$; light soft drinks, $99.0 \%$; pure fruit juice, $88.4 \%$; other fruit juice, $89.0 \%$; smoothies, $87.0 \%$; plain milk, $89.4 \%$; sugared and chocolate milk, $82 \cdot 8 \%$.

IPercentage of the sample who reached the EFSA standard $(1280 \mathrm{ml}$ water from beverages/d).

Table 3 Daily intakes of nine types of beverage $(\mathrm{ml})$ and daily intake of water from beverages (total water; ml) according to gender (adjusted for age and overweight), for the total sample and each country separately. European pre-schoolers (aged 3.5-5.5 years) and their parents/ caregivers ( $n$ 7051), ToyBox-study, May-June 2012

\begin{tabular}{|c|c|c|c|c|c|c|c|c|c|c|c|c|c|c|c|}
\hline & \multirow[b]{2}{*}{ Gender } & \multicolumn{2}{|c|}{ Total } & \multicolumn{2}{|c|}{ Belgium } & \multicolumn{2}{|c|}{ Bulgaria } & \multicolumn{2}{|c|}{ Germany } & \multicolumn{2}{|c|}{ Greece } & \multicolumn{2}{|c|}{ Poland } & \multicolumn{2}{|c|}{ Spain } \\
\hline & & Mean & $x^{2}$ & Mean & $x^{2}$ & Mean & $x^{2}$ & Mean & $x^{2}$ & Mean & $x^{2}$ & Mean & $x^{2}$ & Mean & $x^{2}$ \\
\hline \multirow[t]{2}{*}{ Plain water } & Male & 561 & $23 \cdot 0^{\star \star \star}$ & 406 & 0.6 & 671 & $4 \cdot 3^{*}$ & 491 & 0.5 & 636 & $9 \cdot 1^{* *}$ & 397 & 1.9 & 774 & $17 \cdot 9^{\star \star \star *}$ \\
\hline & Female & 525 & & 394 & & 627 & & 478 & & 582 & & 375 & & 687 & \\
\hline \multirow[t]{2}{*}{ Tea } & Male & 44 & $2 \cdot 0$ & 6 & 1.9 & 65 & $7 \cdot 9^{\star \star}$ & 59 & $3 \cdot 2$ & 6 & $4 \cdot 8^{*}$ & 130 & 0.0 & 2 & 0.1 \\
\hline & Female & 41 & & 4 & & 49 & & 47 & & 11 & & 130 & & 2 & \\
\hline \multirow[t]{2}{*}{ Soft drinks } & Male & 54 & 1.78 & 68 & 0.4 & 34 & 0.7 & 39 & 0.1 & 16 & $4 \cdot 0^{*}$ & 152 & 0.5 & 16 & 1.7 \\
\hline & Female & 49 & & 63 & & 29 & & 40 & & 10 & & 144 & & 13 & \\
\hline \multirow[t]{2}{*}{ Light soft drinks } & Male & 8 & $2 \cdot 9$ & 16 & 0.0 & 14 & 3.1 & 6 & 0.3 & 4 & 0.6 & 4 & 0.8 & 3 & 0.0 \\
\hline & Female & 6 & & 16 & & 7 & & 5 & & 3 & & 3 & & 3 & \\
\hline \multirow[t]{2}{*}{ Pure fruit juice† } & Male & 52 & 1.9 & 17 & 0.8 & 51 & $2 \cdot 8$ & 65 & 0.5 & 112 & 0.5 & 26 & 0.6 & 42 & 0.1 \\
\hline & Female & 49 & & 14 & & 42 & & 60 & & 107 & & 29 & & 40 & \\
\hline \multirow[t]{2}{*}{ Other fruit juiceł } & Male & 108 & $8 \cdot 6^{\star \star}$ & 91 & 0.1 & 105 & $2 \cdot 2$ & 113 & $2 \cdot 9$ & 75 & 0.6 & 184 & 3.4 & 78 & 0.8 \\
\hline & Female & 98 & & 93 & & 91 & & 99 & & 71 & & 166 & & 71 & \\
\hline \multirow[t]{2}{*}{ Smoothies } & Male & 16 & $1 \cdot 1$ & 1 & 3.7 & 12 & 0.4 & 2 & $1 \cdot 4$ & 9 & 0.7 & 25 & 0.0 & 49 & 0.6 \\
\hline & Female & 15 & & 3 & & 10 & & 2 & & 7 & & 25 & & 44 & \\
\hline \multirow[t]{2}{*}{ Plain milk } & Male & 224 & $1 \cdot 7$ & 203 & 0.1 & 110 & $2 \cdot 7$ & 121 & 0.1 & 407 & 0.2 & 162 & 0.1 & 340 & 0.8 \\
\hline & Female & 217 & & 199 & & 96 & & 118 & & 401 & & 160 & & 327 & \\
\hline \multirow[t]{2}{*}{ Sugared and chocolate milk } & Male & 45 & $6 \cdot 2^{*}$ & 95 & $4 \cdot 4^{*}$ & 37 & $1 \cdot 2$ & 27 & 0.4 & 16 & 0.1 & 18 & 0.9 & 84 & 1.0 \\
\hline & Female & 40 & & 79 & & 31 & & 25 & & 15 & & 15 & & 75 & \\
\hline \multirow[t]{2}{*}{ Total water§ } & Male & 1055 & $40 \cdot 4^{\star \star *}$ & 845 & $2 \cdot 4$ & 1056 & $12 \cdot 9^{* * *}$ & 881 & $4 \cdot 2^{*}$ & 1211 & $7 \cdot 1^{\star \star}$ & 1036 & $3.9^{*}$ & 1316 & $15 \cdot 5^{\star \star *}$ \\
\hline & Female & 986 & & 810 & & 943 & & 833 & & 1140 & & 987 & & 1198 & \\
\hline
\end{tabular}

Multilevel analysis, with intakes as dependent variables and gender as independent variable, adjusted for age and overweight.

${ }^{\star} P<0.05,{ }^{\star *} P<0.01,{ }^{\star * \star} P<0.001$.

†Home-made, freshly squeezed.

$\ddagger$ Pre-packed/bottled.

$\S$ Calculated from the water content from the various beverages.

had a high level of education in Polish pre-schoolers, while the opposite was found in Greek pre-school children. The amounts of the different beverages varied also by SES. For plain water, significant differences by SES were found in the total sample and in the Belgian, German and Greek pre-school children, with pre-schoolers of lower-SES mothers consuming less plain water than pre-schoolers of high-SES mothers. For tea, pre-school children of lower-SES mothers drank more tea than pre-schoolers from high-SES mothers in the total sample and in the Greek country-specific sample. 
Table 4 Daily intakes of nine types of beverage $(\mathrm{ml})$ and daily intake of water from beverages (total water; $\mathrm{ml}$ ) according to SES (adjusted for age and overweight), for the total sample and each country separately. European pre-schoolers (aged 3.5-5.5 years) and their parents/ caregivers ( $n$ 7051), ToyBox-study, May-June 2012

\begin{tabular}{|c|c|c|c|c|c|c|c|c|c|c|c|c|c|c|c|}
\hline & \multirow[b]{2}{*}{ SES† } & \multicolumn{2}{|c|}{ Total } & \multicolumn{2}{|c|}{ Belgium } & \multicolumn{2}{|c|}{ Bulgaria } & \multicolumn{2}{|c|}{ Germany } & \multicolumn{2}{|c|}{ Greece } & \multicolumn{2}{|c|}{ Poland } & \multicolumn{2}{|c|}{ Spain } \\
\hline & & Mean & $x^{2}$ & Mean & $x^{2}$ & Mean & $x^{2}$ & Mean & $x^{2}$ & Mean & $x^{2}$ & Mean & $x^{2}$ & Mean & $x^{2}$ \\
\hline Plain water & $\begin{array}{l}\text { Lower } \\
\text { High }\end{array}$ & $\begin{array}{l}530 \\
561\end{array}$ & $13 \cdot 0^{* * *}$ & $\begin{array}{l}364 \\
417\end{array}$ & $8 \cdot 6^{\star \star}$ & $\begin{array}{l}647 \\
660\end{array}$ & 0.3 & $\begin{array}{l}456 \\
519\end{array}$ & $9 \cdot 8^{\star \star}$ & $\begin{array}{l}598 \\
647\end{array}$ & $6 \cdot 8^{* *}$ & $\begin{array}{l}405 \\
386\end{array}$ & $0 \cdot 8$ & $\begin{array}{l}730 \\
745\end{array}$ & 0.4 \\
\hline Tea & $\begin{array}{l}\text { Lower } \\
\text { High }\end{array}$ & $\begin{array}{l}46 \\
40\end{array}$ & $4 \cdot 1^{*}$ & $\begin{array}{l}5 \\
5\end{array}$ & 0.1 & $\begin{array}{l}57 \\
59\end{array}$ & 0.1 & $\begin{array}{l}59 \\
45\end{array}$ & $3 \cdot 6$ & $\begin{array}{r}11 \\
5\end{array}$ & $5 \cdot 1^{*}$ & $\begin{array}{l}139 \\
127\end{array}$ & $1 \cdot 2$ & $\begin{array}{l}1 \\
2\end{array}$ & 0.1 \\
\hline Soft drinks & $\begin{array}{l}\text { Lower } \\
\text { High }\end{array}$ & $\begin{array}{l}65 \\
42\end{array}$ & $41 \cdot 6^{\star \star \star}$ & $\begin{array}{l}99 \\
49\end{array}$ & $33 \cdot 1^{\star * *}$ & $\begin{array}{l}37 \\
27\end{array}$ & $2 \cdot 3$ & $\begin{array}{l}50 \\
27\end{array}$ & $11 \cdot 3^{\star * *}$ & $\begin{array}{l}14 \\
10\end{array}$ & 1.9 & $\begin{array}{l}190 \\
135\end{array}$ & $12 \cdot 7^{\star \star \star}$ & $\begin{array}{l}17 \\
13\end{array}$ & $2 \cdot 2$ \\
\hline Light soft drinks & $\begin{array}{l}\text { Lower } \\
\text { High }\end{array}$ & $\begin{array}{l}9 \\
5\end{array}$ & $19 \cdot 2^{\star \star \star}$ & $\begin{array}{l}24 \\
13\end{array}$ & $9 \cdot 1^{\star *}$ & $\begin{array}{r}14 \\
9\end{array}$ & $1 \cdot 7$ & $\begin{array}{l}6 \\
4\end{array}$ & 0.4 & $\begin{array}{l}5 \\
2\end{array}$ & $8 \cdot 7^{\star *}$ & $\begin{array}{r}67 \\
2\end{array}$ & $9.4^{\star *}$ & $\begin{array}{l}4 \\
3\end{array}$ & 1.9 \\
\hline Pure fruit juice $\ddagger$ & $\begin{array}{l}\text { Lower } \\
\text { High }\end{array}$ & $\begin{array}{l}48 \\
51\end{array}$ & 0.9 & $\begin{array}{l}15 \\
16\end{array}$ & $0 \cdot 1$ & $\begin{array}{l}41 \\
48\end{array}$ & $1 \cdot 1$ & $\begin{array}{l}61 \\
63\end{array}$ & $0 \cdot 1$ & $\begin{array}{l}104 \\
112\end{array}$ & $1 \cdot 2$ & $\begin{array}{l}33 \\
26\end{array}$ & $1 \cdot 8$ & $\begin{array}{l}36 \\
44\end{array}$ & $2 \cdot 2$ \\
\hline Other fruit juice§ & $\begin{array}{l}\text { Lower } \\
\text { High }\end{array}$ & $\begin{array}{l}106 \\
100\end{array}$ & $2 \cdot 4$ & $\begin{array}{l}98 \\
90\end{array}$ & $0 \cdot 6$ & $\begin{array}{r}90 \\
101\end{array}$ & $1 \cdot 2$ & $\begin{array}{l}109 \\
103\end{array}$ & 0.4 & $\begin{array}{l}73 \\
69\end{array}$ & 0.6 & $\begin{array}{l}187 \\
171\end{array}$ & $1 \cdot 6$ & $\begin{array}{l}79 \\
68\end{array}$ & 1.9 \\
\hline Smoothies & $\begin{array}{l}\text { Lower } \\
\text { High }\end{array}$ & $\begin{array}{l}18 \\
14\end{array}$ & $13 \cdot 4^{\star \star \star}$ & $\begin{array}{l}3 \\
3\end{array}$ & 0.0 & $\begin{array}{r}9 \\
11\end{array}$ & 1.0 & $\begin{array}{l}2 \\
2\end{array}$ & 0.5 & $\begin{array}{l}8 \\
4\end{array}$ & $7 \cdot 3^{\star *}$ & $\begin{array}{l}35 \\
21\end{array}$ & $22 \cdot 8^{\star \star \star}$ & $\begin{array}{l}52 \\
45\end{array}$ & 1.3 \\
\hline Plain milk & $\begin{array}{l}\text { Lower } \\
\text { High }\end{array}$ & $\begin{array}{l}218 \\
224\end{array}$ & 1.4 & $\begin{array}{l}178 \\
211\end{array}$ & $5 \cdot 3^{*}$ & $\begin{array}{r}99 \\
103\end{array}$ & 0.3 & $\begin{array}{l}109 \\
120\end{array}$ & 1.5 & $\begin{array}{l}399 \\
426\end{array}$ & $3 \cdot 2$ & $\begin{array}{l}183 \\
159\end{array}$ & $4 \cdot 8^{*}$ & $\begin{array}{l}352 \\
329\end{array}$ & 1.7 \\
\hline Sugared and chocolate milk & $\begin{array}{l}\text { Lower } \\
\text { High }\end{array}$ & $\begin{array}{l}46 \\
41\end{array}$ & $3 \cdot 9^{*}$ & $\begin{array}{r}100 \\
82\end{array}$ & $4 \cdot 2^{*}$ & $\begin{array}{l}34 \\
34\end{array}$ & 0.0 & $\begin{array}{l}26 \\
26\end{array}$ & $0 \cdot 0$ & $\begin{array}{l}18 \\
13\end{array}$ & 1.5 & $\begin{array}{l}27 \\
14\end{array}$ & $10 \cdot 0^{\star \star}$ & $\begin{array}{l}79 \\
83\end{array}$ & $0 \cdot 1$ \\
\hline Total waterll & $\begin{array}{l}\text { Lower } \\
\text { High }\end{array}$ & $\begin{array}{l}1028 \\
1024\end{array}$ & $0 \cdot 1$ & $\begin{array}{l}827 \\
829\end{array}$ & 0.0 & $\begin{array}{r}990 \\
1010\end{array}$ & 0.4 & $\begin{array}{l}835 \\
874\end{array}$ & $2 \cdot 3$ & $\begin{array}{l}1161 \\
1219\end{array}$ & $4 \cdot 4^{*}$ & $\begin{array}{r}1136 \\
987\end{array}$ & $21 \cdot 7^{\star \star \star}$ & $\begin{array}{l}1279 \\
1264\end{array}$ & 0.2 \\
\hline
\end{tabular}

SES, socio-economic status.

Multilevel analysis, with intakes as dependent variables and SES as independent variable, adjusted for age and overweight.

${ }^{\star} P<0.05,{ }^{* \star} P<0.01,{ }^{* * \star} P<0.001$.

†SES indicator is years of school education of the mother: lower, mother of the child has $\leq 14$ years of education; high, mother of the child has $>14$ years of education.

†Home-made, freshly squeezed.

§Pre-packed/bottled.

IICalculated from the water content from the various beverages.

In the total sample and in three countries (Belgium, Germany and Poland) significant differences were found for soft drinks. Pre-school children of lower-SES mothers drank more soft drinks. In addition, pre-schoolers from lower-SES backgrounds consumed twice as much light soft drinks compared with pre-schoolers of higher-SES backgrounds. These results were seen for the total sample and after stratification also in three out of six countries (Belgium, Greece and Poland).

No significant results were found for pure fruit juice and other fruit juice for the total sample, nor in the country-specific samples. Lower-SES pre-schoolers drank more smoothies compared with high-SES pre-schoolers in the total sample and in Greece and Poland.

No significant results were found for plain milk in the total sample and mixed results were seen in the countryspecific samples. In Polish pre-schoolers, plain milk was significantly more consumed by lower-SES pre-school children than by high-SES pre-school children. Opposite results for plain milk were found in Belgian pre-schoolers, namely Belgian pre-school children of lower-SES mothers consumed less plain milk than pre-school children from high-SES mothers. In the total sample and in Belgian and Polish pre-school children, lower-SES pre-schoolers drunk more sugared and chocolate milk than their highSES peers.

\section{Discussion}

The aim of the present study was to investigate the quantity of water intake from beverages and the quality of beverages consumed by pre-schoolers of six European countries, as well as their relationships with gender and SES (educational level of the mother).

Since prolonged dehydration can have negative health effects, it is important that the water intake meets the standard $^{(30,31)}$. In the present study, a mean water intake from beverages of $1050.5 \mathrm{ml} / \mathrm{d}$ was found in the total sample. Compared with the EFSA standard of $1280 \mathrm{ml}$ water from beverages daily, in general the mean water intake found in the current study was too low. Only $28.1 \%$ of the pre-schoolers met the standard. Because of the diversity in how water intake is measured (e.g. water from beverages, daily consumption of beverages, etc.), comparison between studies can be difficult ${ }^{(7)}$.

In a study of Flemish children aged between 2.5 and 6.5 years, a total water intake (both from food and beverages) of slightly more than $1300 \mathrm{ml} / \mathrm{d}$ was found ${ }^{(4)}$. If we assume that $80 \%$ (or $1040 \mathrm{ml}$ ) of the water intake was derived from beverages, the intake is comparable with the results found in the present study. In our study, water intake was found to be especially low in Western European countries with, respectively, $8.1 \%$ and $14.1 \%$ of 
the Belgian and German pre-schoolers reaching the EFSA standard. Water intake was higher in Southern European countries, with $42.2 \%$ of Greek and $50.4 \%$ of Spanish pre-school children reaching the EFSA norm. This might be due to a warmer climate in these countries in comparison with other parts of Europe ${ }^{(32)}$. The higher water intake in Greece and Spain was derived mainly from a higher consumption of plain water and milk.

Furthermore, some differences in water intake from beverages by gender and SES could be found. In the total sample, pre-school boys had a higher water intake than girls, which was also confirmed in all countries except for Belgium. Pre-school children of lower-SES mothers had a higher water intake than their peers of high-SES backgrounds in Poland, while opposite results were found in Greek pre-school children. In short, male pre-schoolers scored better on quantity of water intake from beverages than their female peers and mixed results were found for SES.

The standards for water intake discussed above cover only the quantity of water intake and do not give any recommendation about the quality of the chosen beverages. Quality of the chosen beverage is, in addition to quantity, also of importance since beverages can be a considerable source of unnecessary energy for children. Plain water should be the main source of water intake since plain water does not provide additional energy intake; this is an important factor to maintain a healthy energy balance and prevent obesity ${ }^{(33,34)}$. Although plain water was the most important water source in the present study, only slightly more than half of the water intake was derived from plain water. Tea, without added sugar, can also be a good water source but it was a small water contributor in the current sample ${ }^{(33)}$. In addition, nearly a quarter of the water intake, i.e. $277 \cdot 1 \mathrm{ml}$, was derived from milk (either plain milk or sugared and chocolate milk). Pre-schoolers should consume $500 \mathrm{ml}$ milk daily to reach their $\mathrm{Ca}$ intake. This norm also includes yoghurt and derivatives ${ }^{(35)}$. So milk is, in addition to water, a major source of water intake in this age group ${ }^{(2)}$.

In addition to these preferred water sources, also the consumption of other beverages was studied. An excessive intake of added sugars, e.g. through soft drinks, can lead to an energy imbalance and thus to overweight ${ }^{(36-39)}$. In the total sample, about $5 \%$ of water intake came from soft drinks. It was expected that this volume would be higher when taking earlier studies into account. In the Canadian Community Health Survey Nutrition conducted in 2004, 20.8\% of daily energy was derived from beverages in 4 - to 8 -year-old boys and $18.1 \%$ in girls of the same age, of which, respectively, 5 and $4 \%$ came from sweetened drinks ${ }^{(16)}$. Considering the present results, soft drink consumption of European pre-schoolers appears to be limited. In the total sample of the current study, only a small percentage $(0.6 \%)$ of water intake came from light soft drinks. Replacing soft drinks by artificially sweetened beverages is not encouraged, as the safety and benefits of using artificial sweeteners in young children are still inconclusive $^{(40)}$. Furthermore, fruit juices accounted for $15.5 \%$ of total water intake from beverages and represented, in addition to water and milk, the third most important source of water. These beverages (pure fruit juices, other fruit juices and smoothies) also contain a lot of sugars. Although these are containing fruit sugars instead of artificially added sugars, they are not recommended as important water sources given the extra energy they supply ${ }^{(33)}$. In addition, evidence suggests that consuming liquid energy generally produces less satiety than solid forms, so an excessive intake of fruit juices should be avoided ${ }^{(41)}$. Based on the results found in the current study, it appears that European parents are already aware of the adverse health effects of soft drinks but still have insufficient knowledge about the high sugar content of fruit juices. This finding was also found in the ENERGY project, in which it could be deduced that parents had a misconception about whether or not fruit juices are a healthy choice ${ }^{(42)}$. Therefore, information on the quality of beverages, especially fruit juices, should be the focus of future interventions on water intake and beverage consumption in pre-schoolers. This was also found in a study of Rader et al., who concluded that future interventions should focus not only on sugar-sweetened beverages to reduce energy intake form beverage consumption, but also on fruit juices, since these are important contributors of energy intake from beverages, especially in young children ${ }^{(14)}$. However, it is also important to continue spreading the message that soft drinks are not good water sources, even after pre-schoolers have outgrown infancy, as an increasing consumption of soft drinks is noticeable when they get older ${ }^{(2,11,12)}$.

Analyses by gender showed only limited differences in quality of the chosen beverages. Male pre-schoolers had a higher consumption of plain water, soft drinks, other fruit juice, and sugared and chocolate milk. Nevertheless this was not confirmed in all countries. The higher consumption of fruit juice in boys was also found in a Canadian study of 4 - to 8 -year-olds ${ }^{(16)}$. Several studies on pre-school children show a difference in soft drink consumption by gender: boys consumed more soft drinks than girls ${ }^{(5,16,17)}$. This could only be confirmed in Greek pre-schoolers in the present study.

Our study showed some differences in quality of the consumed beverages in terms of SES. As stated earlier, pre-school children of lower-SES mothers consumed more water from beverages in Polish pre-schoolers. This higher quantity is not due to a higher consumption of plain water, but to a higher intake of sugared beverages. Pre-school children of lower-SES backgrounds in the total sample and in Belgium, Germany and Greece consumed less plain water than their peers of high-SES backgrounds. In addition, pre-schoolers of lower-SES backgrounds consumed more soft drinks (in the total 
sample and in three countries), more light soft drinks (in the total sample and in three countries) and more sugared and chocolate milk (in the total sample and in two countries) than their peers with high-SES mothers. Previous studies have only found evidence for the relationship between SES and sweetened beverage intake, and between SES and obesity. Food intake or consumption of sweetened beverages can differ by SES in children, which can lead to a difference in obesity prevalence. Obesity is more prevalent in children of lower-SES backgrounds ${ }^{(18,19)}$. The results on soft drinks found in the current study are in line with those from a study on Flemish children aged 2.5-7 years and a study in eight European countries among children aged 2-9 years, in which lower-SES children consumed more soft drinks than high-SES children ${ }^{(20,28)}$. Several explanations can be provided for the differences in quality of the chosen beverages according to SES. First, parents play an important role in food and beverage consumption of young children. It has been found that lower-SES mothers also consume more soft drinks than high-SES mothers, which is a significant factor given the important influence of role modelling by parents on children's dietary behaviours ${ }^{(43)}$. Also the higher availability, accessibility and permissiveness of soft drinks for lower-SES children have been found to explain the differences in consumption between lower- and high-SES children ${ }^{(44)}$. A difference in other parenting practices between high- and lower-SES mothers may explain the differences in permissiveness according to SES. Lower-SES mothers often lack the skills to impose restrictions on the consumption of unhealthy foods and the skills to reinforce positive behaviour ${ }^{(43)}$. In addition, high-SES parents often take health more into account than lower-SES parents ${ }^{(43)}$. Furthermore, lower-SES parents are more difficult to reach with health messages ${ }^{(45)}$. In lowerSES parents, knowledge problems might occur since the educational level of the mother was used as an indicator for SES. Kant and Graubard indicated that 'education may be linked to acquisition, understanding, and implementation of knowledge about desirable dietary behaviors' (p. 690) ${ }^{(46)}$. Parents can reason that pure fruit juice is a healthy water source because it is made of $100 \%$ fruit but they often forget that this also creates an additional intake of sugars and thus extra energy ${ }^{(47)}$. Light soft drinks can be seen as a healthier replacement for regular soft drinks due to the lower sugar content, but as stated earlier there are still many uncertainties about the use of artificial sweeteners in children ${ }^{(40)}$. Information on beverage choices should be clear to everyone and tailored to the target public. So communication tailored to the SES level of the parents could provide a solution. More specifically, particularly lower-SES parents should be informed about the quality of the beverages their children consume.

The present study has some limitations. The information on water intake was collected with an FFQ filled out by the parents/caregivers. There might be a bias in these parental self-reports caused by socially desirable answers and under-reporting ${ }^{(48)}$. However, this was partially covered by ensuring anonymity. In addition, González-Gil et al. have studied the reliability of primary caregivers' reports and concluded that 'a primary caregivers questionnaire is a reliable tool to assess socio-demographic characteristics, perinatal factors and lifestyle behaviours of pre-school children and their families participating in the ToyBoxintervention' (p. 61) ${ }^{(49)}$.

The FFQ of Huybrechts et al., on which the FFQ used in the present study was based, was specifically designed for use by parents of pre-school children. However, it did not specifically target children who spend time in child care, which could be a source of error. Nevertheless, the FFQ of Huybrechts et al. has already been validated using a sample of children collected through kindergartens and the results showed moderate to good reproducibility (intra-class correlation coefficients ranged from 0.62 to 0.79 ) and good relative validity (Spearman correlation coefficients ranged from 0.56 to 0.65 ) for beverages ${ }^{(24)}$.

The total water intake is calculated based on the Dutch food composition database because there is no European database yet. However, the Dutch food composition database is very similar to those in other countries, making it applicable for a European population. The advantage of using one food composition database is that it makes comparison between the different countries in our study possible. Since SES was assessed only by the educational level of the mother, pre-school children living in a family with a father having a higher educational level than the mother were assessed as having a lower educational status. However, educational level has been identified as an important indicator for SES and maternal education is often seen as more influencing for the child than education of the father given that mothers are often the primary caregiver $^{(44,50)}$. This was also found in a study of De Coen et al. in which only maternal education was found as a risk factor for overweight in pre-school children and no significant results were found for paternal education ${ }^{(51)}$. We acknowledge that the ToyBox-study sample is not a fully representative European sample, due to sampling in specific regions in each country. However, limited differences can be found between regions within European countries. Samples included pre-schoolers of low-, medium- and high-SES backgrounds and in each kindergarten (almost) complete classes were included. The samples can give a fair approximation of the average situation in each country. The procedure of sampling in specific regions has also been used in several other European studies such as HELENA (Healthy Lifestyle in Europe by Nutrition in Adolescence) and ENERGY ${ }^{(52,53)}$. In addition, the SES distribution of the sample may not be the same as the actual SES distribution in each country. The SES group samples were not weighted to reflect the actual SES distribution in each country, not resulting in truly representative population samples, and this has to be 
taken into account while interpreting the results. Also, as the present study was cross-sectional, no causality in relationships could be identified. Longitudinal data are needed to study the change in water and beverage intake throughout childhood. In addition, the limited number of significant results after stratification could be due to a lack of power in the sub-samples. However, the significant country-specific results indicate the strength of the relationships. Analyses were not controlled for unobserved variables such as protein intake and health status since these variables were not questioned in the ToyBox-study. This could possibly affect the results. However, analyses were adjusted for age and weight status to adjust for possible covariates.

To our knowledge, the present study is the first one that examined the quantity and quality of water intake from beverages in European pre-schoolers and their relationship with SES and gender. Moreover, research in pre-school children is scarce, as this is an under-reported age group. Another strength of the study is the large sample of preschoolers from six European countries and the standardized data collection protocol across the different countries.

\section{Conclusion}

The quantity of water intake from beverages in the majority of the European pre-schoolers does not meet the EFSA standard of $1280 \mathrm{ml} / \mathrm{d}$. Especially in Western European countries, there is a low water intake from beverages. Regarding the quality of water intake, the most important water sources were plain water, milk and fruit juices. Also soft drinks and light soft drinks were consumed, but only in small amounts. The largest problem regarding quality is the high consumption of fruit juices. Moreover, differences in intake were found by gender with boys having a higher intake but scoring worse on quality of the water intake. Also, lower-SES pre-school children did consume more water from beverages than high-SES children; however, the chosen beverages of lower-SES children were of lower quality compared with the high-SES children, mainly due to a higher consumption of soft drinks, light soft drinks and fruit juices. Interventions aiming at a proper and sufficient water intake in pre-schoolers across Europe should not only target the quantity of water intake, but also the quality of the water sources. Messages about water sources should focus on reducing fruit juice and soft drink consumption, especially in pre-schoolers of lower-SES parents. Also, interventions should emphasize that soft drink consumption should be limited as children get older.

\section{Acknowledgements}

Financial support: The ToyBox-study is funded by the Seventh Framework Programme (CORDIS FP7) of the
European Commission under grant agreement no. 245200. The sponsor had no role in the design or conduct of the study, the collection, management, analysis or interpretation of the data, or the preparation, review and approval of the manuscript. The content of this article reflects only the authors' views and the European Community is not liable for any use that may be made of the information contained therein. Conflict of interest: None. Authorship: All authors participated in the ToyBoxstudy and in the study design. All authors read, critically reviewed the manuscript and approved the final manuscript. A.-S.P. wrote the manuscript. Ethics of buman subject participation: The ToyBox-study was approved by ethics committees in all six European countries, in line with national regulations. The ToyBox-study group consists of the following: Co-ordinator: Yannis Manios; Steering Committee: Yannis Manios, Berthold Koletzko, Ilse De Bourdeaudhuij, Mai Chin A Paw, Luis Moreno, Carolyn Summerbell, Tim Lobstein, Lieven Annemans, Goof Buijs; External Advisors: John Reilly, Boyd Swinburn, Dianne Ward; Harokopio University (Greece): Yannis Manios, Odysseas Androutsos, Eva Grammatikaki, Christina Katsarou, Eftychia Apostolidou, Eirini Efstathopoulou; Ludwig Maximilians Universitaet München (Germany): Berthold Koletzko, Kristin Duvinage, Sabine Ibrügger, Angelika Strauß, Birgit Herbert, Julia Birnbaum, Annette Payr, Christine Geyer; Ghent University (Belgium), Department of Movement and Sports Sciences: Ilse De Bourdeaudhuij, Greet Cardon, Marieke De Craemer, Ellen De Decker and Department of Public Health: Lieven Annemans, Stefaan De Henauw, Lea Maes, Carine Vereecken, Jo Van Assche, Lore Pil; VU University Medical Center, EMGO Institute for Health and Care Research (the Netherlands): Mai Chin A Paw, Saskia te Velde; University of Zaragoza (Spain): Luis Moreno, Theodora Mouratidou, Juan Fernandez, Maribel Mesana, Pilar De Miguel-Etayo, Esther González, Luis Gracia-Marco, Beatriz Oves; Oslo and Akershus University College of Applied Sciences (Norway): Agneta Yngve, Susanna Kugelberg, Christel Lynch, Annhild Mosdøl; University of Durham (UK): Carolyn Summerbell, Helen Moore, Wayne Douthwaite, Catherine Nixon; State Institute of Early Childhood Research (Germany): Susanne Kreichauf, Andreas Wildgruber; Children's Memorial Health Institute (Poland): Piotr Socha, Zbigniew Kulaga, Kamila Zych, Magdalena Góźdź, Beata Gurzkowska, Katarzyna Szott; Medical University of Varna (Bulgaria): Violeta Iotova, Mina Lateva, Natalya Usheva, Sonya Galcheva, Vanya Marinova, Zhaneta Radkova, Nevyana Feschieva; International Association for the Study of Obesity (UK): Tim Lobstein, Andrea Aikenhead; National Institute for Health Promotion and Disease Prevention (the Netherlands): Goof Buijs, Annemiek Dorgelo, Aviva Nethe, Jan Jansen; AOK- Verlag (Germany): Otto Gmeiner, Jutta Retterath, Julia Wildeis, Axel Günthersberger; Roehampton University (UK): Leigh Gibson; University of Luxembourg (Luxembourg): Claus Voegele. 


\section{References}

1. Popkin BM, D'Anci KE \& Rosenberg IH (2010) Water, hydration and health. Nutr Rev 68, 439-458.

2. Bellisle F, Thornton SN, Hébel P et al. (2010) A study of fluid intake from beverages in a sample of healthy French children, adolescents and adults. Eur J Clin Nutr 64, 350-355.

3. Manz F \& Wentz A (2003) 24-h hydration status: parameters, epidemiology and recommendations. Eur J Clin Nutr 57, Suppl. 2, S10-S18.

4. Huybrechts I \& De Henauw S (2007) Energy and nutrient intake by pre-school children in Flanders-Belgium. Br J Nutr 98, 600-610.

5. Craigie AM, Lake AA, Kelly SA et al. (2011) Tracking of obesity-related behaviours from childhood to adulthood: a systematic review. Maturitas 70, 266-284.

6. Fiorito LM, Marini M, Mitchell DC et al. (2010) Girls' early sweetened carbonated beverage intake predicts different patterns of beverage and nutrient intake across childhood and adolescence. J Am Diet Assoc 110, 543-550.

7. EFSA Panel on Dietetic Products, Nutrition, and Allergies (2010) Scientific opinion on dietary reference values for water. EFSA J 8, 1459.

8. Panel on Dietary Reference Intakes for Electrolytes and Water (2005) Dietary Reference Intakes for Water, Potassium, Sodium, Chloride, and Sulfate. Washington, DC: The National Academies Press.

9. Huybrechts I, Matthys C, Vereecken C et al. (2008) Food intake by preschool children in Flanders compared with dietary guidelines. Int J Environ Res Public Health 5, 243-257.

10. Iglesia I, Guelinckx I, De Miguel-Etayo PM et al. (2015) Total fluid intake of children and adolescents: crosssectional surveys in 13 countries worldwide. Eur J Nutr 54, 57-67.

11. Drewnowski A, Rehm CD \& Constant F (2013) Water and beverage consumption among children age $4-13 y$ in the United States: analyses of 2005-2010 NHANES data. Nutr J 12, 85 .

12. Feferbaum R, de Abreu LC \& Leone C (2012) Fluid intake patterns: an epidemiological study among children and adolescents in Brazil. BMC Public Health 12, 1005.

13. Reedy J \& Krebs-Smith SM (2010) Dietary sources of energy, solid fats, and added sugars among children and adolescents in the United States. J Am Diet Assoc 110, 1477-1484.

14. Rader RK, Mullen KB, Sterkel R et al. (2014) Opportunities to reduce children's excessive consumption of calories from beverages. Clin Pediatr 53, 1047-1054.

15. LaRowe TL, Moeller SM \& Adams AK (2007) Beverage patterns, diet quality, and body mass index of US preschool and school-aged children. J Am Diet Assoc 107, 1124-1133.

16. Garriguet D (2008) Beverage consumption of children and teens. Health Rep 19, 17-22.

17. Fenández-Alvira JM, Iglesia I, Ferreira-Pêgo C et al. (2014) Fluid intake in Spanish children and adolescents; a crosssectional study. Nutr Hosp 29, 1163-1170.

18. Caprio S, Daniels SR, Drewnowski A et al. (2008) Influence of race, ethnicity, and culture on childhood obesity: implications for prevention and treatment. Diabetes Care 31, 2211-2221.

19. Danielzik S, Czerwinski-Mast M, Langnäse K et al. (2004) Parental overweight, socioeconomic status and high birth weight are the major determinants of overweight and obesity in 5-7 y-old children: baseline data of the Kiel Obesity Prevention Study (KOPS). Int J Obes Relat Metab Disord 28, 1494-1502.

20. Fernández-Alvira JM, Mouratidou T, Bammann $\mathrm{K}$ et al. (2013) Parental education and frequency of food consumption in European children: the IDEFICS study. Public Health Nutr 16, 487-498.
21. Sohn W, Heller KE \& Burt BA (2001) Fluid consumption related to climate among children in the United States. J Public Health Dent 61, 99-106.

22. Manios Y, Grammatikaki E, Androutsos O et al. (2012) A systematic approach for the development of a kindergartenbased intervention for the prevention of obesity in preschool age children: the ToyBox-study. Obes Rev 13, 3-12.

23. Manios Y, Androutsos O, Katsarou C et al. (2014) Designing and implementing a kindergarten-based, family-involved intervention to prevent obesity in early childhood: the ToyBox-study. Obes Rev 15, 5-13.

24. Huybrechts I, De Backer G, De Bacquer D et al. (2009) Relative validity and reproducibility of a food-frequency questionnaire for estimating food intakes among Flemish preschoolers. Int J Environ Res Public Health 6, 382-399.

25. National Institute for Public Health and the Environment (2013) About NEVO-data. http://www.rivm.nl/en/Topics/ D/Dutch_Food_Composition_Database/About_NEVO_data (accessed January 2014).

26. De Miguel-Etayo P, Mesana MI, Cardon G et al. (2014) Reliability of anthropometric measurements in European preschool children: the ToyBox-study. Obes Rev 15, 67-73.

27. Cole TJ \& Lobstein T (2012) Extended international (IOTF) body mass index cut-offs for thinness, overweight and obesity. Pediatr Obes 7, 284-294.

28. Brug J, van Stralen MM, te Velde SJ et al. (2012) Differences in weight status and energy-balance related behaviors among schoolchildren across Europe: the ENERGY-project. PLoS One 7, E34742.

29. Mouratidou T, Miguel ML, Androutsos O et al. (2014) Tools, harmonization and standardization procedures of the impact and outcome evaluation indices obtained during a kindergarten-based, family-involved intervention to prevent obesity in early childhood: the ToyBox-study. Obes Rev 15, 53-60.

30. Kleiner SM (1999) Water: an essential but overlooked nutrient. J Am Diet Assoc 99, 200-206.

31. Steiner MJ, DeWalt DA \& Byerley JS (2004) Is this child dehydrated? JAMA 291, 2746-2754.

32. World Meteorological Organization (2014) World Weather Information Service: Europe. http://worldweather.wmo.int/ en/region.html?ra=6 (accessed January 2014).

33. Vanhauwaert E (2012) Water. In De actieve voedingsdrieboek, pp. 37-41. Leuven: Acco.

34. Agostoni C, Braegger C, Decsi T et al. (2011) Role of dietary factors and food habits in the development of childhood obesity: a commentary by the ESPGHAN Committee on Nutrition. J Pediatr Gastroenterol Nutr 52, 662-669.

35. Food and Agriculture Organization of the United Nations (2013) Milk and dairy products as part of the diet. In Milk and Dairy Products in Human Nutrition, pp. 103-206 [E Muehlhoff, A Bennett and D McMahon, editors]. Rome: FAO.

36. Briefel RR, Wilson A, Cabili C et al. (2013) Reducing calories and added sugars by improving children's beverages choices. I Acad Nutr Diet 113, 269-675.

37. Marshall TA, Levy SM, Broffitt B et al. (2003) Dental caries and beverage consumption in young children. Pediatrics 112, E184-E191.

38. DeBoer MD, Scharf RJ \& Demmer RT (2013) Sugarsweetened beverages and weight gain in 2- to 5-year-old children. Pediatr 132, 413-420.

39. Sylvetsky A, Rother KI \& Brown R (2011) Artificial sweetener use among children: epidemiology, recommendations, metabolic outcomes, and future directions. Pediatr Clin North Am 58, 1467-1480.

40. De Ruyter JC, Olthof MR, Seidell JC et al. (2012) A trial of sugar-free or sugar-sweetened beverages and body weight in children. $N$ Engl J Med 367, 1397-1406. 
41. Pan A \& Hu FB (2011) Effects of carbohydrates on satiety: differences between liquid and solid food. Curr Opin Clin Nutr Metab Care 14, 385-390.

42. Van Lippevelde W, te Velde SJ, Verloigne M et al. (2013) Associations between home- and family-related factors and fruit juice and soft drink intake among 10- to 12-year old children. The ENERGY project. Appetite 61, 59-65.

43. Vereecken CA, Keukelier E \& Maes L (2004) Influence of mother's educational level on food parenting practices and food habits of young children. Appetite 43, 93-103.

44. De Coen V, Vansteelandt S, Maes L et al. (2012) Parental socioeconomic status and soft drink consumption of the child. The mediating proportion of parenting practices. Appetite 59, 76-80.

45. O'Malley AS, Kerner JF \& Johnson L (1999) Are we getting the message out to all? Health information sources and ethnicity. Am J Prev Med 17, 198-202.

46. Kant AK \& Graubard BI (2013) Family income and education were related with 30-year time trends in dietary and meal behaviors of American children and adolescents. J Nutr 143, 690-700.

47. De Creamer M, De Decker E, De Bourdeaudhuij I et al. (2013) Physical activity and beverage consumption in preschoolers: focus groups with parents and teachers. BMC Public Health 13, 278.
48. Tooze JA, Subar AF, Thompson FE et al. (2004) Psychosocial predictors of energy underreporting in a large doubly labeled water study. Am J Clin Nutr $\mathbf{7 9}$, 795-804.

49. González-Gil EM, Mouratidou T, Cardon G et al. (2014) Reliability of primary caregivers reports on lifestyle behaviours of European pre-school children: the ToyBox-study. Obes Rev 15, 61-66.

50. Williams SK \& Kelly FD (2005) Relationships among involvement, attachment, and behavioral problems in adolescence: examining father's influence. J Early Adolesc 25, 168-196.

51. De Coen V, De Bourdeaudhuij I, Verbestel V et al. (2014) Risk factors for childhood overweight: a 30-month longitudinal study of 3- to 6-year-old children. Public Health Nutr 17, 1993-2000.

52. Moreno LA, De Henauw S, González-Gross M et al. (2008) Design and implementation of the Healthy Lifestyle in Europe by Nutrition in Adolescence Cross-Sectional Study. Int J Obes (Lond) 32, 5-11.

53. van Stralen MM, te Velde SJ, Singh AS et al. (2011) EuropeaN Energy balance Research to prevent excessive weight Gain among Youth (ENERGY) project: design and methodology of the ENERGY cross-sectional survey. BMC Public Health 11, 65. 